\title{
Overshoot of HIV-1 viraemia after early discontinuation of antiretroviral treatment
}

\author{
Menno D. de Jong*, Rob J. de Boer ${ }^{\dagger}$, Frank de Wolf ${ }^{\ddagger}$, \\ Norbert A. Foudraine*\$ ${ }^{*}$, Charles A.B. Boucher", Jaap Goudsmit ${ }^{\ddagger}$ \\ and Joep M.A. Lange*
}

Objective: To determine whether, as predicted by predator-prey dynamics, early withdrawal of antiretroviral therapy, i.e., when the number of CD4+ lymphocytes is still elevated, results in an overshoot of HIV-1 viraemia due to infection of increased numbers of available target cells at that time.

Design and methods: Five HIV-1-infected individuals were identified who discontinued antiretroviral therapy for various reasons after 8-19 days, and from whom stored serum samples obtained before, during, and shortly after treatment were available for measurement of HIV-1 RNA load. A mathematical model was designed to assess whether increased target cell availability could quantitatively explain the clinical observations.

Results: After therapy withdrawal, increases in the HIV-1 RNA load to levels exceeding pretreatment values by $\log _{10} 0.6-1.5$ copies $/ \mathrm{ml}$ were observed after $2-17$ days in all four of the individuals who had treatment-induced increases in CD4+ cell counts at the time of therapy withdrawal. Increases in viraemia were maximal within a few days, and subsequently seemed to wane until the pretreatment equilibrium between virus and its target cells was attained. Mathematical modelling confirms that these transient increases in viraemia can be explained by increased availability of target cells at the time of therapy withdrawal.

Conclusions: Transient rises in HIV-1 viraemia do occur following early therapy withdrawal. These rises especially warrant consideration in short-term antiretroviral regimens for prevention of mother-to-child transmission, as are being studied in developing countries, since they could result in an increased transmission risk during the post-partum period through breast-feeding. This possibility needs to be investigated urgently.

AIDS 1997, 11:F79-F84

Keywords: HIV-1, virus load, antiretroviral therapy, withdrawal, predator-prey

From the *Department of Internal Medicine, Division of Infectious Diseases, Tropical Medicine \& AIDS, National AIDS Therapy Evaluation Centre, Academic Medical Centre, University of Amsterdam, Amsterdam, the ${ }^{\dagger}$ Department of Theoretical Biology, Utrecht University, Utrecht, the ${ }^{\ddagger}$ Department of Human Retrovirology, Academic Medical Centre, University of Amsterdam, the ${ }^{\S}$ Department of Health and Environment, Municipal Health Service, Amsterdam and the ${ }^{1 \prime}$ Eijkman-Winkler Institute, Department of Virology, Academic Hospital, Utrecht University, Utrecht, The Netherlands.

Requests for reprints to: Dr Menno D. de Jong, Department of Medical Microbiology, Academic Medical Center, L1-104, Meibergdreef 9, 1105 AZ Amsterdam, The Netherlands.

Date of receipt: 1 May 1997; accepted: 30 May 1997. 


\section{Introduction}

Although infection with HIV-1 is characterized by an extremely rapid turnover of virus and infected cells [1-3], the level of circulating virus and the number of peripheral CD4+ lymphocytes are relatively stable in the short term. This indicates a balance between high levels of viral replication and a rapid renewal of CD4+ target cells. This quasi-equilibrium is perturbed by the institution of antiretroviral treatment, which results in a reduction of the virus load, accompanied by a rise in the number of CD4+ lymphocytes, presumably due to protection of target cells from novel infections. It can be hypothesized that, in the case of incomplete suppression of the viral replication, the increased number of CD4+ cells provides the virus with more target cells, resulting in increased production of virus [4]. We have previously demonstrated that, during zidovudine treatment, increased target cell availability can explain an initial resurgence in virus load that precedes the development of drug-resistance [5]. Assuming that availability of target cells indeed plays a role in determining the virus load during treatment, early withdrawal of suppressive therapy, at a time when the number of CD4+ cells are still elevated, would be expected to result in a transient overshoot of HIV-1 viraemia to levels exceeding the pretreatment values. In view of the dynamics of HIV-1 infection, such an overshoot would occur very soon after therapy withdrawal.

To assess whether a burst of viraemia indeed occurs following early discontinuation of therapy, we identified five HIV-1-infected individuals who stopped treatment soon after the institution of therapy for various reasons, and from whom serum samples, obtained shortly after withdrawal of therapy, were available. In these subjects, serum HIV-1 RNA load was assessed during and after treatment. A mathematical model was designed to assess whether increased target cell availability could quantitatively explain our clinical observations.

\section{Patients and methods}

Five HIV-1-infected individuals were identified who received antiretroviral treatment for a short period of time and from whom stored serum samples obtained before, during, and shortly after discontinuation of treatment were available. The characteristics of these individuals are shown in Table 1 . The subjects were treated with either the protease inhibitor indinavir (subjects A, B), or the non-nucleoside reverse transcriptase inhibitor nevirapine (subjects D, E), in one patient (person D) alternating with zidovudine, for a period ranging from 8 to 19 days. They stopped treatment for various reasons. Follow-up after discontinuation of treatment ranged from 8 to 24 days (Fig. 1). In subject A, treatment was reinstituted after 24 days of interruption (Fig. 1). The HIV-1 RNA load was measured in serum samples stored at $-70^{\circ} \mathrm{C}$, using a quantitative nucleic acid sequence-based amplification (NASBA) technique [6]. In addition, the serum levels of immune complex-dissociated p24 antigen were measured in three subjects who were p24 antigen-positive (individuals $\mathrm{C}-\mathrm{E}$ ), using a commercially available enzyme linked immunosorbent assay (Coulter, Hialeah, Florida, USA). The CD4+ lymphocyte counts had been assessed at regular intervals.

\section{Results}

\section{Virus load and CD4+ cells during treatment}

The HIV-1 RNA load declined during treatment in all five subjects (Fig. 1). Observed maximum decreases ranged from 0.66 to $1.87 \log$ RNA copies $/ \mathrm{ml}$. At the time of therapy withdrawal, the virus load was still below the baseline values in all subjects (range, -1.51 to $-0.33 \log$ copies $/ \mathrm{ml}$ ). In subject A, the virus load increased substantially prior to therapy withdrawal. Note that, in this individual, a similar resurgence was observed during the second treatment period, after which the virus load remained approximately $\log _{10}$ below pretreatment values until the last assessment at 4 weeks after reinstitution of treatment. Since the virus appeared sensitive to the drug during the second treatment period, the initial resurgences were unlikely to be caused by the development of drug-resistance. In view of the marked rises in CD4+ cell counts during both

Table 1. Patient characteristics.

\begin{tabular}{|c|c|c|c|c|c|c|}
\hline \multirow[b]{2}{*}{ Subject } & \multicolumn{3}{|c|}{ Pretreatment } & \multirow[b]{2}{*}{ Treatment (drug/dose) } & \multirow[b]{2}{*}{$\begin{array}{l}\text { Duration } \\
\text { (days) }\end{array}$} & \multirow[b]{2}{*}{ Reason for withdrawal } \\
\hline & $\begin{array}{l}\text { CD4+ cells } \\
\left(\text { cells } \times 10^{6} / \mathrm{l}\right)\end{array}$ & $\begin{array}{c}\text { HIV-1 RNA load } \\
\text { (log copies/ml) }\end{array}$ & $\begin{array}{c}\text { ICD p24 antigen } \\
(\mathrm{pg} / \mathrm{ml})\end{array}$ & & & \\
\hline $\bar{A}$ & $<10$ & 7.53 & - & Indinavir 800 mg t.i.d. & $19^{*}$ & Transaminase levels rise $^{\ddagger}$ \\
\hline $\mathrm{B}$ & 20 & 4.87 & _- & Indinavir 800 mg t.i.d. & 19 & Neurological deterioration \\
\hline $\mathrm{C}$ & 10 & 4.66 & 117 & $\begin{array}{l}\text { Nevirapine } 200 \mathrm{mg}^{\circ} \text { o.d. } \\
\text { Zidovudine } 200 \mathrm{mg}^{\dagger} \text { t.i.d. }\end{array}$ & $7 / 5^{+}$ & Nausea \\
\hline $\mathrm{D}$ & 160 & 5.88 & 94 & Nevirapine 200 mg o.d. & 8 & Rash \\
\hline $\mathrm{E}$ & 170 & 5.74 & 168 & Nevirapine 200 mg o.d. & 13 & Rash \\
\hline
\end{tabular}

*Treatment was reinstituted after 24 days of interruption. ${ }^{\dagger}$ Seven days nevirapine, followed by 5 days zidovudine. ${ }^{\ddagger}$ Increased transaminase levels were later demonstrated to be secondary to disseminated Mycobacterium avium infection and antimycobacterial treatment was not instituted during the interruption of antiretroviral therapy. t.i.d., Three times a day; o.d., once a day. 

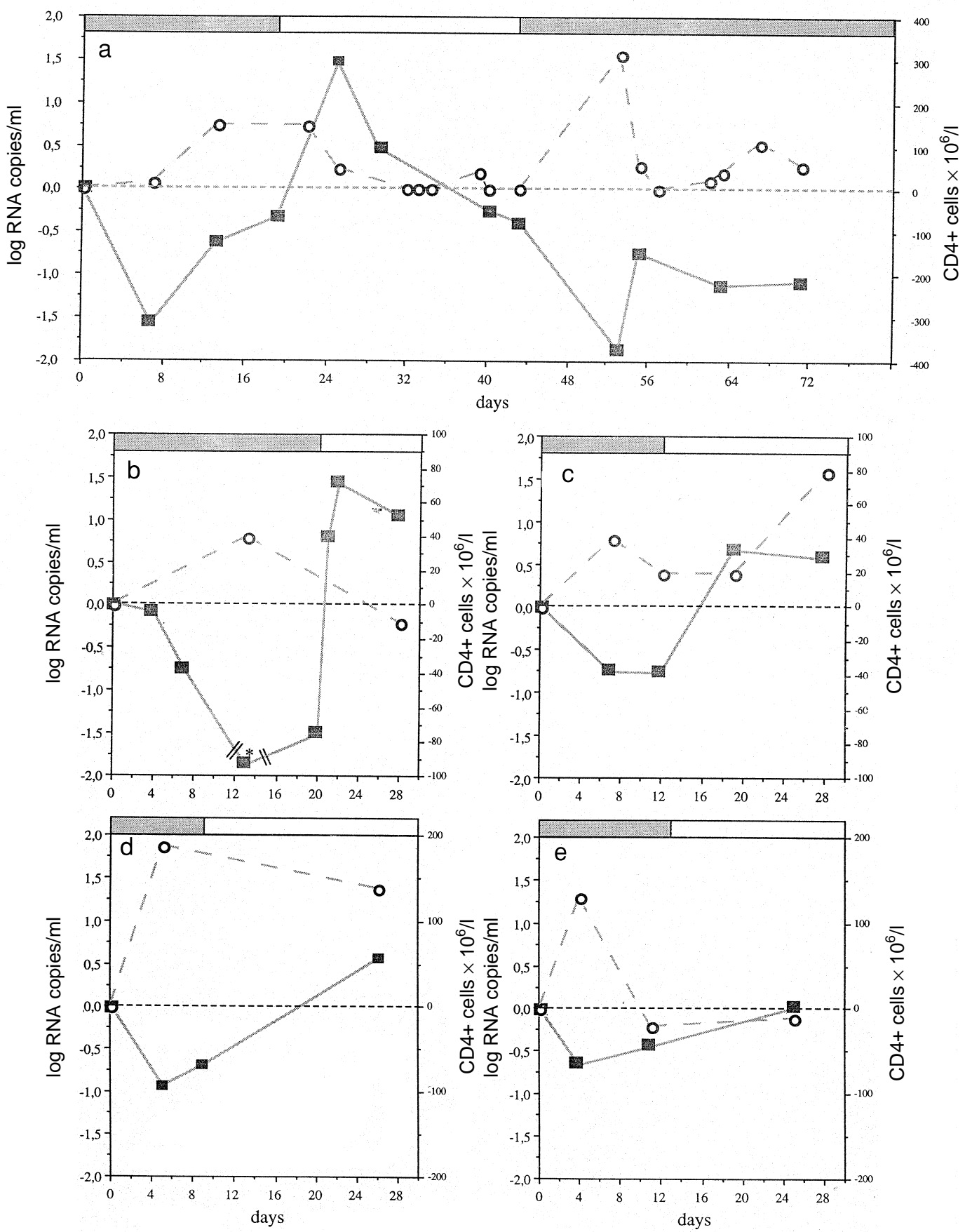

Fig. 1. Changes in HIV-1 RNA load $(\mathbf{\square})$ and CD4+ cell counts $(\bigcirc)$ in five HIV-1-infected individuals during antiretroviral treatment, and following therapy withdrawal. The horizontal bars indicate whether treatment is received (shaded) or not (nonshaded). *Below the detection limit of the assay $\left(10^{3}\right.$ copies $\left./ \mathrm{ml}\right)$.

treatment periods, a resurgence of wild-type virus due to increased target cell availability may be the more likely explanation $[5]$.

The declines in virus load in the five subjects were paralleled by increases in CD4+ cell counts; maximum rises from pretreatment values ranged from 40 to 190 cells $\times 10^{6} / 1$. Around the time of therapy withdrawal, CD4+ cell counts were still increased in four of the five subjects. In subject $\mathrm{E}$, the CD4+ cell count had already returned to pretreatment values at that time, presumably due to the emergence of drug-resistant virus variants. In this patient, the complete HIV-1 RNA population in serum at day 25 was shown to harbour the nevirapine resistance-conferring $\mathrm{Y} 181 \mathrm{C}$ amino acid change in HIV-1 reverse transcriptase (data not shown) [7].

\section{Virus load and CD4+ cells after treatment}

Following discontinuation of treatment, increases in virus load were observed in four of the five subjects, 
reaching levels ranging from $\log _{10} 0.57-1.46$ above pretreatment values (Fig. 1). In two of the three p24 antigen-positive patients (C and D), this was paralleled by an increase in p24 antigen levels to 95 and 293\% above pretreatment values, respectively.

The largest increases in virus load were observed in serum samples obtained during the first week after discontinuation of therapy. When considering all of the serum samples obtained from the five subjects after therapy withdrawal $(\mathrm{n}=11)$, regression analysis showed a significant inverse correlation between the elapsed number of days since withdrawal of therapy and the changes in virus load from pretreatment values (correlation coefficient $=0.69, P=0.0015)$ (Fig. 2). Taken together, these observations suggest that an overshoot of HIV-1 viraemia occurs within days after therapy withdrawal, which subsequently wanes over the next weeks until the pretreatment equilibrium between the virus and its target cells is attained. This is substantiated by the course of the virus load in subject $A$, who was the individual studied in most detail (Fig. 1a). As shown in subjects $\mathrm{A}$ and $\mathrm{B}$, from whom the earliest samples after therapy withdrawal were available, the overshoot in viraemia can be extremely large. The observed increases in subjects $\mathrm{C}$ and $\mathrm{D}$ possibly are underestimations of the actual maximal increases, since the maximal burst of viraemia may have preceded the first timepoint at which the virus load was measured. In subject $\mathrm{E}$, an increase in serum HIV-1 RNA load to levels exceeding the baseline values was not observed and the p24 antigen levels remained low after discontinuation of treatment. It was noted that the CD4+ lymphocyte count in this individual had already returned to the pretreatment value at the time of therapy withdrawal, and viral resistance to nevirapine had already developed.

\section{Predator-prey dynamics and the overshoot in viraemia}

We developed a simple mathematical model to study whether the large overshoots in HIV-1 RNA load can indeed be explained by increased availability of CD4+ target cells at the time of therapy withdrawal. Our model is similar to an ecological Lotka-Volterra predator-prey model, where a prey, in this case the CD4+ target cell, is eaten by a predator, i.e., HIV-1. Such a model aims at elegance and simplicity, and allows one to derive results that are generic, i.e., results that should be independent of the model details.

Our model has been described in detail before $[5,8]$. In short, we assume that HIV-1 can only establish productive infection in activated $\mathrm{T}$ cells [9]. Since only a fraction of CD4+ T cells is activated, and hence is a target cell for HIV-1, we distinguished resting CD4+ T cells $R$, and activated target CD4+ T cells $T$. The activation of resting cells at a rate $\alpha$ gives rise to target cells, which divide and return to the resting stage at rate $\beta$.

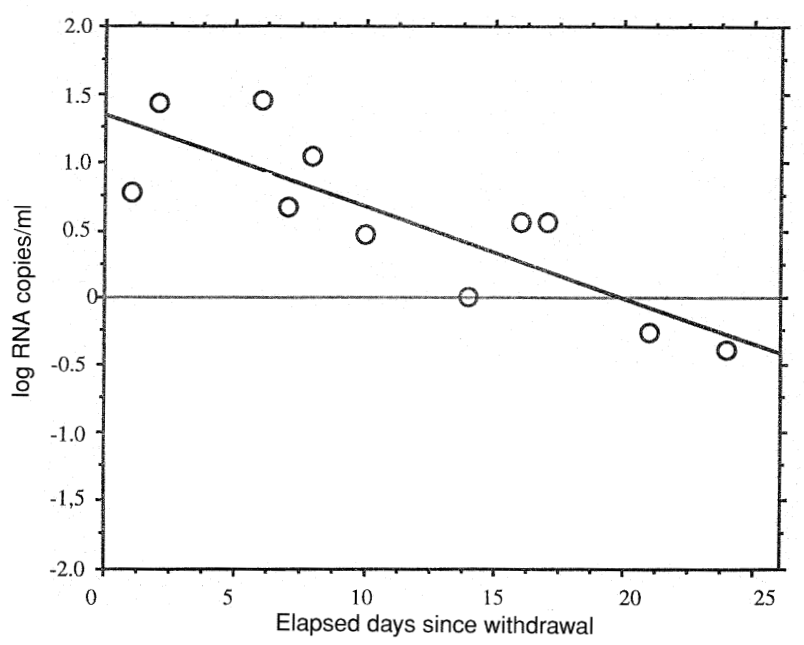

Fig. 2. The changes from baseline in HIV-1 RNA load in relation to the number of elapsed days since therapy withdrawal in all five subjects. The line represents the regression line (correlation coefficient $=0.69, P=0.0015$ ) .

Resting $\mathrm{T}$ cells have a life-time of $1 / \mathrm{d}_{\mathrm{R}}$ days. HIV-1 infection is implemented in the system by considering infectious virions $V$, which infect target cells at a rate $\gamma$. The resulting productively-infected cells $I$ have a lifetime of $1 / \mathrm{d}_{\mathrm{I}}$ days, and produce new viruses at a rate of $\rho$ virions/cell per day. The expected life-time of virions is $1 / \mathrm{c}$ days.

This translates in the following set of differential equations:

$$
\begin{aligned}
& \frac{\mathrm{d} R}{\mathrm{~d} t}=2 \beta T-\alpha R-\mathrm{d}_{\mathrm{R}} R, \\
& \frac{\mathrm{d} T}{\mathrm{~d} t}=\alpha R-\beta T-\gamma T V, \\
& \frac{\mathrm{d} I}{\mathrm{~d} t}=\gamma T V-\mathrm{d}_{\mathrm{I}} I, \\
& \frac{\mathrm{d} V}{\mathrm{~d} t}=\rho I-\mathrm{c} V,
\end{aligned}
$$

Some of the parameters in the model are well established. The turnover rates of productively infected cells and infectious virions have been estimated to be $\mathrm{d}_{\mathrm{I}}=0.5$ per day, and $\mathrm{c}=3$ per day respectively [3]. Since resting $\mathrm{T}$ cells are long lived [10], we set the lifetime of resting cells to be 100 days, i.e., $d_{R}=0.01$ per day. The viral load is scaled such that $\rho=1$. Although it is not known at what rate an activated $\mathrm{T}$ cell reverts to the resting stage, we assumed that a $\mathrm{T}$ cell remains activated for approximately two days, and set $\beta=0.5$ per day. The remaining parameters are the activation rate $\alpha$, and the infection rate $\gamma$ in the absence and presence of antiretroviral treatment. 
We fit these unknown parameters to the observations in subject A, from whom the most detailed data were available. The CD4+ cell count prior to treatment was only 10 cells $\times 10^{6} / 1$, and the virus load was very high. We therefore assumed that the fraction of activated CD4+ T cells, i.e., the target cells, should be high. By setting $\alpha=0.3$ per day, we obtain that, before the initiation of treatment, $25 \%$ of the uninfected $\mathrm{T}$ cells are target cells. We tune the infection rate to $\gamma=0.5$, such that a CD4+ cell count of 10 cells $\times 10^{6} / 1$ before start of treatment is obtained.

Figure 3 shows a simulation of the model in which treatment with indinavir is started at day zero and is stopped at day 19. The pretreatment situation reflects the steady-state equilibrium which corresponds to the equilibrium of equation $(1 \mathrm{a}-\mathrm{d})$. We model indinavir treatment by reducing the infection rate 10 -fold between days zero and 19. Similar to the in vivo observations in subject $A$, the virus load declines to $2 \%$ of the pretreatment values, accompanied by a 17 -fold rise of the CD4+ cell count. After withdrawal of treatment, an 'explosion' of virus load to levels exceeding pretreatment values by 27 -fold is observed within $2-3$ days. Since this model behaviour corresponds closely to the in vivo observations, we conclude that an increased availability of target cells can indeed be responsible for the observed large overshoots in the virus load following early withdrawal of treatment.

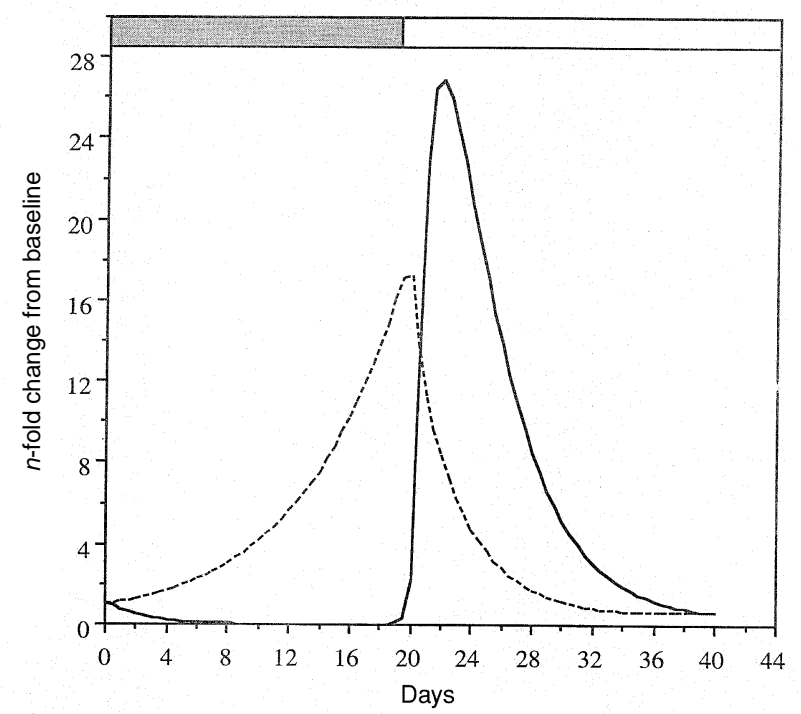

Fig. 3. $n$-fold-changes in virus load (solid) and CD4+ cells (dotted) during treatment and after therapy withdrawal, as simulated in our model. The horizontal bar indicates whether treatment is received (shaded) or not (non-shaded). The pretreatment situation corresponds to the steady-state equilibrium of equation ( $1 \mathrm{a}-\mathrm{d}$ ) for $\gamma=0.5$. Treatment with indinavir is simulated by setting $\gamma=0.05$ between days 0 and 19.

\section{Discussion}

Based on previous studies on the impact of increased target cell availability on virus load during antiretroviral therapy $[4,5]$, we predicted that early discontinuation of antiretroviral treatment could lead to a transient overshoot of HIV-1 viraemia. We were able to assess the short-term effects on virus load of early therapy withdrawal in five HIV-1-infected individuals. Our observations suggest that increases in virus load do indeed occur immediately after discontinuation of antiretroviral treatment. These increases may be extremely large, and are at a maximum during the first few days after therapy withdrawal, subsequently waning over the next few weeks. In this respect, the overshoots in HIV1 RNA load actually resemble the burst of viraemia during acute infection. The enormous potential of increased viral replication following therapy withdrawal is illustrated by subject B in our study, who showed a 1000 -fold increase in virus load within 2 days after therapy withdrawal.

Our conjecture is that the overshoot in HIV-1 viraemia after early therapy withdrawal is due to the increased availability of target cells. It is noteworthy that in the one subject in our study whose virus load did not appear to exceed pretreatment values, the number of CD4+ cells had already returned to the pretreatment values before treatment was discontinued, which is supportive of this hypothesis. A simple mathematical model suggests that increased target cell availability can indeed account for the observed large overshoots in viraemia. Furthermore, the model supports our notion that the virus load increases most rapidly during the first few days after therapy withdrawal, and subsequently decreases towards pretreatment values due to the loss of available CD4+ target cells. Similarly, it has previously been suggested that the reduction in virus load following the burst of viraemia during acute infection is due to exhaustion of the permissive host cells, rather than to the onset of an effective immune response [11].

Although the data in this study are limited, and confirmation in larger series is needed, our observations may have important implications. Most importantly, the risk of transmission of HIV-1 to others may be increased during the transient rise in viraemia. In this respect, special concern is warranted regarding mother-to-child transmission of HIV. High levels of maternal virus load may be associated with an increased risk of mother-tochild transmission [12-14]. In the developing countries, several clinical studies are in progress to evaluate the potential efficacy of short-term antiretroviral treatment regimens, instituted shortly prior to or at delivery, in preventing intra-partum mother-to-child transmission. However, it is well established that breast-feeding also carries a substantial risk of HIV transmission $[15,16]$. Moreover, it has been suggested that the risk of trans- 
mission through breast-feeding is enhanced during a primary infection of the mother due to the burst of viraemia that is generally observed in this period $[17,18]$. It was noted that the overshoots in viraemia following therapy withdrawal in our study actually resemble the viraemic burst during primary HIV infection. If a similar overshoot in viraemia occurs after completion of short-term prophylactic antiretroviral regimens in pregnant women, the risk of transmission in the post-partum period through breast-feeding may thus be increased, thereby diminishing the prophylactic efficacy of these regimens. This possibility needs to be investigated urgently.

\section{References}

1. Wei X, Ghosh SK, Taylor ME, et al.: Viral dynamics in human immunodeficiency virus type $\mathbf{1}$ infection. Nature 1995 373:117-122.

2. Ho DD, Neumann AU, Perelson AS, Chen W, Leonard JM, Markowitz M: Rapid turnover of plasma virions and CD4 lymphocytes in HIV-1 infection. Nature 1995, 373:123-126.

3. Perelson AS, Neumann AU, Markowitz M, Leonard JM, Ho DD: HIV-1 dynamics in vivo: virion clearance rate, infected cell lifespan, and viral generation time. Science 1996, 271:1582-1586.

4. McLean AR, Emery VC, Webster A, Griffiths PD: Population dynamics of HIV within an individual after treatment with zidovudine. AIDS 1991, 5:485-489.

5. De Jong MD, Veenstra J, Stilianakis NI, et al.: Host-parasite dynamics and outgrowth of virus containing a single K70R amino acid change in reverse transcriptase are responsible for the loss of human immunodeficiency virus type 1 RNA load suppression by zidovudine. Proc Natl Acad Sci USA 1996, 93:5501-5506.
6. Van Gemen B, Van Beuningen R, Nabbe A, et al.: A one-tube quantitative HIV-1 RNA NASBA nucleic acid amplification assay using electrochemiluminescent (ECL) labelled probes. J Virol Methods 1994, 49:157-167.

7. Richman DD, Havlir D, Corbeil J, et al.: Nevirapine resistance mutations of human immunodeficiency virus type 1 selected during therapy. J Virol 1994, 68:1660-1666.

8. Stilianakis NI, Boucher CAB, De Jong MD, Van Leeuwen R, Schuurman R, De Boer RJ: Clinical data sets of human immunodeficiency virus type 1 reverse transcriptase-resistant mutants explained by a mathematical model. J Virol 1997, 71: 161-168.

9. Bukrinsky MI, Stanwick TL, Dempsey MP, Stevenson M: Quiescent T lymphocytes as an inducible virus reservoir in HIV1 infection. Science 1991, 254:423-427.

10. McLean AR, Michie CA: In vivo estimates of division and death rates of human T lymphocytes. Proc Natl Acad Sci USA 1995, 92:3707-3711.

11. Phillips AN: Reduction of HIV concentration during acute infection: independence from a specific immune response. Science 1996, 271:497-499.

12. Dickover RE, Garratty E, Herman, SA, et al.: Identification of levels of maternal HIV-1 RNA associated with risk of perinatal transmission. JAMA 1996, 275: 599-605.

13. Sperling RS, Shapiro DE, Coombs RW, et al.: Maternal viral load, zidovudine treatment, and the risk of transmission of human immunodeficency virus type 1 from mother to infant. N Engl J Med 1996, 335: 1621-1629.

14. Thea DM, Steketee RW, Pliner V, et al.: The effect of maternal viral load on the risk of perinatal transmission of HIV-1. AIDS 1997, 11: 437-444.

15. Dunn DT, Newell ML, Ades AE, Peckham CS: Risk of human immunodeficiency virus type 1 transmission through breastfeeding. Lancet 1992, 340: 585-588.

16. De Martino M, Tovo PA, Tozzi AE, et al.: HIV-1 transmission through breast-milk: appraisal of risk according to duration of feeding. AIDS 1992, 6:991-997.

17. Van de Perre $\mathrm{P}$, Simonon A, Msellati $\mathrm{P}$, et al.: Postnatal transmission of human immunodeficiency virus type 1 from mother to infant. N Engl J Med 1991, 325: 593-598.

18. Palasanthiran P, Ziegler JB, Stewart GJ, et al.: Breast-feeding during primary maternal human immunodeficiency virus infection and risk of transmission from mother to infant. J Infect Dis 1993, 167: 441-444. 